\title{
Use of insulin pump therapy is associated with reduced hospital-days in the long-term: a real-world study of 48,756 pediatric patients with type 1 diabetes
}

\author{
Marie Auzanneau ${ }^{1,2}$ (D) $\cdot$ Beate Karges $^{3} \cdot$ Andreas Neu $^{4} \cdot$ Thomas Kapellen $^{5} \cdot$ Stefan A. Wudy $^{6} \cdot$ Corinna Grasemann $^{7}$. \\ Gabriele Krauch $^{8} \cdot$ Eva Maria Gerstl $^{9} \cdot$ Gerhard Däublin $^{10} \cdot$ Reinhard W. Holl $^{1,2}$
}

Received: 18 June 2020 / Revised: 22 October 2020 / Accepted: 20 November 2020 / Published online: 1 December 2020

(C) The Author(s) 2020

\begin{abstract}
In pediatric diabetes, insulin pump therapy is associated with less acute complications but inpatient pump education may lead to more hospital days. We investigated the number of hospital days associated with pump vs. injection therapy between 2009 and 2018 in 48,756 patients with type 1 diabetes < 20 years of age from the German Diabetes Prospective Follow-up Registry (DPV). Analyses were performed separately for hospitalizations at diagnosis (hierarchical linear models adjusted for sex, age, and migration), and for hospitalizations in the subsequent course of the disease (hierarchical Poisson models stratified by sex, age, migration, and therapy switch). At diagnosis, the length of hospital stay was longer with pump therapy than with injection therapy (mean estimate with 95\% CI: 13.6 [13.3-13.9] days vs. 12.8 [12.5-13.1] days, $P<0.0001$ ), whereas during the whole follow-up beyond diagnosis, the number of hospital days per person-year (/PY) was higher with injection therapy than with pump therapy (4.4 [4.1-4.8] vs. 3.9 [3.6-4.2] days/PY), especially for children under 5 years of age (4.9 [4.4-5.6] vs. 3.5 [3.1-3.9] days/PY).

Conclusions: Even in countries with hospitalizations at diabetes diagnosis of longer duration, the use of pump therapy is associated with a reduced number of hospital days in the long-term.
\end{abstract}

Keywords Hospitalization · Hospital days $\cdot$ Insulin pump therapy $\cdot$ Children $\cdot$ Type 1 diabetes

$\begin{array}{ll}\text { Abbreviations } & \\ \text { BMI } & \text { Body mass index } \\ \text { CI } & \text { Confidence interval } \\ \text { DKA } & \text { Diabetic ketoacidosis } \\ \text { DPV } & \text { German Diabetes Prospective Follow-up } \\ & \text { Registry }\end{array}$

Communicated by Gregorio Paolo Milani

Marie Auzanneau

marie.auzanneau@uni-ulm.de

Beate Karges

bkarges@ukaachen.de

Andreas Neu

andreas.neu@med.uni-tuebingen.de

Thomas Kapellen

ThomasMichael.Kapellen@medizin.uni-leipzig.de

Stefan A. Wudy

Stefan.Wudy@paediat.med.uni-giessen.de
LMS method Method using lambda-mu-sigma parameters

PY Person-year

SDS Standard deviation score

\author{
Corinna Grasemann \\ corinna.grasemann@klinikum-bochum.de \\ Gabriele Krauch \\ gabriele.krauch@umm.de \\ Eva Maria Gerstl \\ EvaMaria.Gerstl@kinderklinik-passau.de \\ Gerhard Däublin \\ gerhard.daeublin@u-e-k.de \\ Reinhard W. Holl \\ reinhard.holl@uni-ulm.de
}

Extended author information available on the last page of the article 
What is known:

- In pediatric diabetes, insulin pump therapy is associated with better glycemic control and less acute complications compared with injection therapy.

- However, pump therapy implies more costs and resources for education and management.

What is new:

- Even in countries where pump education is predominantly given in an inpatient setting, the use of pump therapy is associated with a reduced number of hospital days in the long-term.

- Lower rates of hospitalization due to acute complications during the course of the disease counterbalance longer hospitalizations due to initial pump education

\section{Introduction}

In children and adolescents with type 1 diabetes, the use of diabetes technology has rapidly increased worldwide. For instance in the USA [1], in Nordic countries [2], and in Germany or Austria [3], the majority of patients aged $<15$ years use insulin pump therapy. In agreement with the growing evidence that insulin pump therapy is associated with better glycemic control [4], less acute complications [5], and lower cardiovascular mortality [6] compared to injection therapy, most health care providers judge insulin pump therapy as safe and effective. In addition, preadolescent children and caregivers report substantial psychosocial benefits and improved quality of life in relation with the use of insulin pumps [7].

However, pump therapy remains more expensive than injection therapy [8]. Pump therapy implies not only more material costs but also more resources and time spent for education and management [8]. Currently, practices of insulin pump initiation, education, and training vary a lot around the world [9, 10]. For instance, in New Zealand, both out- and inpatient approaches of pump initiation and training have been described [9]. In the USA, pump training typically occurs several months after diagnosis and is done completely outpatient. By contrast, in other countries like in Sweden, Austria, or Germany, pump initiation and education mostly occur in an inpatient setting $[10,11]$. German guidelines for instance particularly recommend pump therapy (beside many other criteria) for all newborns, infants, and preschoolers, and for these children, pump therapy is mostly initiated during a one or two weeks hospitalization immediately after diagnosis $[5,11,12]$.

Inpatient management and education for diabetes technology may lead to an increased number of hospital days for children using pump therapy. On the other hand, studies have shown that the use of pump therapy is associated with a lower number of hospital stays due to acute complications (diabetic ketoacidosis [DKA] or severe hypoglycemia) compared to injection therapy [5]. Therefore, in countries with predominantly inpatient diabetes education, there is still an uncertainty whether the use of pump therapy is associated with a lower or with a higher number of hospital days compared with injection therapy in the long-term.
In the present study, we investigated the number of hospital days per person-year between 2009 and 2018 associated with the use of insulin pump therapy vs. injection therapy in 48,756 pediatric patients with type 1 diabetes in Germany.

\section{Material and methods}

\section{Study population}

For this population-based cohort study, we used data from the multicenter Diabetes Prospective Follow-up (DPV) Initiative based at the University of Ulm, Germany. Since 1995, all hospitals and practices participating in the DPV registry, mainly located in Germany and Austria, prospectively document clinical and demographic data of patients with any type of diabetes. The documentation is done both manually and automatically (download from clinic information systems) into the predefined database DPV, a diabetes-specific electronic health record. Every 6 months, the collected data is transmitted after verification in anonymous form to the University of Ulm. Subsequently, the university of Ulm reports implausible data back to centers, and performs central analysis and quality assurance. The Ethics Committee of the Medical Faculty of the University of Ulm, as well as the local review boards of participating centers, approved both data collection and analysis of anonymized data from the DPV database.

Since data documentation in the DPV registry is closely controlled, many variables (e.g., sex, age, diabetes duration, or migration status) have no missing values. Other data, like hospital days, are not completely documented. However, hospital days in the DPV database are extracted from administrative data collected by the diabetes center, relevant for reimbursement, and as such their documentation is particularly controlled by the hospital and by external controllers, for example, by the health insurance companies.

As of March 2019, data of 556,021 patients from 485 diabetes centers were documented in the database. For this analysis, we included all patients with a clinical diagnosis of type 1 diabetes at the age of six months or later, aged $<20$ years, living in Germany, documented between January 1, 2009, and December 31, 2018, with at least two visits (outpatient or inpatient), and available documentation of insulin pump therapy or insulin injection therapy. Hospital stays longer than 
three weeks were set to 21 days, considering that other causes, not related to diabetes or diabetes therapy may have led to such exceptional length of stay. Patients from countries outside of Germany were excluded due to differences between national health systems.

\section{Explanatory variables}

In order to adjust for differences between local laboratories, we standardized individual $\mathrm{HbAlc}$ values to the Diabetes Control and Complications Trial reference of 4.05-6.05\%, using the "multiple-of-the-mean" transformation method [13]. We transformed BMI $\left(\mathrm{kg} / \mathrm{m}^{2}\right)$ values as standard deviation score (SDS) to adjust for age and gender, using a German reference population [14] and the LMS method [15]. Age was categorized in four groups: 0.5 to $<5$ years, 5 to $<10$ years, 10 to $<15$ years, and 15 to $<20$ years. Migration background was defined as birth of the patient himself or at least one of his parents outside of Germany.

\section{Statistical analysis}

We separately investigated the number of hospital days associated with pump or injection therapy for the period of diagnosis and during the subsequent course of the disease.

For the period of diagnosis, we performed hierarchical linear regression models adjusting for sex, age group, and migration background, and presented results as number of hospital days at diagnosis with $95 \%$ confidence interval $(95 \%$ CI). As not all patients are hospitalized on the day of diagnosis, we used a time-interval of 9 days before and after the date of diagnosis to identify hospitalizations related to the onset of diabetes. If the day of admission to the hospital fell within this period, then the entire length of the hospital day was considered to represent the hospitalization at onset of diabetes (i.e., at diagnosis). Patients hospitalized with reason "onset" 10 days or more after diagnosis were assumed to have been identified as patient with presymptomatic diabetes by previous screening. We excluded those patients ( $n=990)$ as they are generally more informed about diabetes and usually do not experience the typical sudden manifestation of the disease [16].

For the investigation of hospitalization during the course of the disease (hospital admission 10 days or more after diabetes diagnosis), we performed hierarchical Poisson regression analyses taking into consideration for each patient the individual cumulative time at risk spent with each treatment modality between 2009 and 2018. Results are given as number of hospital days per person-year (/PY) with 95\% CI. Time at risk and number of hospital days, both related with either injection therapy or pump therapy, were summed up, including within patients with therapy switch. Other parameters were aggregated as median.
For hospital stays with a switch of therapy, we divided the number of hospital days half-and-half into days with pump and days with injection therapy. We also performed a sensitivity analysis to test other ways of dividing the days allocated to the previous and to the new therapy (30-70\%, or $20-80 \%$ respectively), considering the possibility of a planned switch, which rather occurs at the beginning of the hospital stay, or of a delayed switch, which is decided during the hospitalization period. If hospital stay with a switch of therapy was the last documented visit, we only took into account half the number of days (or $30 \%$ and $20 \%$ respectively in the sensitivity analysis), and allocated them to the therapy modality of the beginning of the hospital stay, as hospital days of the new treatment could not be related to a sufficient observation time with the new therapy.

Regression models were stratified by sex, age group, and migration background. Additionally, we performed the Poisson regression analysis in the subgroup of patients with at least one therapy switch, assuming that patients who have used pump therapy continuously and those who have used injection therapy continuously may have different baseline characteristic associated with both the choice of the therapy and their hospitalization risk (confounding by indication). We analyzed for each patient the cumulative time spent with injection therapy and the cumulative time spent with pump therapy separately. Thus, comparisons were conducted within the same patients, so that baseline characteristics were identical. Moreover, we considered the direction of the switch and repeated the analysis within patients who switched at least once from injection to pump, from pump to injection, and in both directions.

In a second step, we investigated with the same Poisson regression models the number of hospital days per person-year associated with pump or injection therapy for the most frequent admission causes documented in the DPV registry, namely: DKA, severe hypoglycemia, and diabetes education.

We used random intercept models (variable "diabetes center" included as a random effect, with Cholesky parameterization of an unstructured covariance matrix) to take into account the possible hierarchical structure of the data (patients from the same center are supposed to have more similar characteristics than patients from two different centers). All regression analyses were complete case analyses. We present descriptive data as median (interquartile range, IQR) for continuous variables or percentage for categorical variables. Wilcoxon test was used for comparison of continuous variables and $X^{2}$ test was used to compare variables with binomial distribution. Due to the large size of the study population, the level of significance of two-sided tests was set at $P<0.01$, as generally recommended in biostatistical textbooks. All statistical analyses were performed with SAS 9.4 (SAS Institute, Cary, NC, USA). 


\section{Results}

\section{Characteristics of the study population}

Of 84,344 patients with a clinical diagnosis of type 1 diabetes at the age of 6 months or later aged $<20$ years from the DPV registry, 79,241 were living in Germany; 55,234 were documented between January 1, 2009, and December 31, 2018; 49,427 had at least two visits (outpatient or inpatient); and for 48,756 (our final study population), the documentation of insulin pump therapy or insulin injection therapy was available.

\section{Analysis for the period of diagnosis}

Among all patients included, 22,434 children had data documented during the first 9 days around diagnosis (Table 1). At diagnosis, the large majority of children were treated with insulin injections $(n=18,080 ; 80.6 \%)$. Of those children, 3,092 (17.1\%) used conventional insulin therapy (CT) (1-3 daily injection time points), and 14,988 (82.9\%) used intensified insulin therapy (ICT) / basis bolus therapy ( $>3$ daily injection time points). Children who received pump therapy at diagnosis were in median younger than those using injection therapy ( 3.7 years vs. 10.9 years, $P<0.0001$, Table 1 ). At diagnosis, the length of hospital stay was longer with pump therapy, even after adjustment for sex, age group, and migration background (13.6 [95\%-CI: 13.3-13.9] vs. 12.8 [12.513.1] days, $P<0.0001$, Table 2$)$.

\section{Analysis during the subsequent course of the disease}

Of 48,647 patients with data documented beyond the period of diagnosis, $24,408(50.2 \%)$ used injection therapy continuously (2007 on CT and 22,401 on ICT), whereas 10,459 (21.5\%) used only pump therapy (Table 3). Among 13,780 (28.3\%) patients who switched between both therapy options, 13,234 switched at least once from injection to pump, 3,388 switched at least once from pump to injection, and 2,842 patients switched in both directions (Fig. 1d).

Compared with individuals who used injection therapy continuously, those who used only pump therapy during the subsequent course of the disease were in median five years younger, had earlier diabetes onset, and less often a migration background (Table 3 , all $P<0.0001$ ). Among the children and adolescents who used both therapy modalities, there was a majority of girls ( $52.0 \%$ vs. $46.8 \%$ in the study population), and of patients aged 10 to $<15$ years $(53.5 \%$ vs. $40.4 \%$ in the study population) (Table 3 ). Median HbAlc was similar $(7.6 \%)$ in all groups (Table 3 ).

Over the 10 years of follow-up beyond the period of diagnosis, the number of hospital days per person-year was higher with injection than with pump therapy (unadjusted mean estimate with $95 \%$ CI: 4.4 [4.1-4.8] vs. 3.9 [3.6-4.2] days/PY, $P$ $<0.0001)$. Stratified by age group, sex, migration status, or therapy change (continuous use or switch), the results were similar, with a higher number of hospital days per person-year associated with injection therapy than with pump therapy (Fig. 1, all comparisons significant with $P<0.0001)$. The largest difference was observed for children under 5 years of age, with 4.9 [4.4-5.6] days/PY associated with injection therapy vs. 3.5 [3.1-3.9] days/PY associated with pump therapy, $P<$ 0.0001 (Fig. 1a). Even in the 13,780 children and adolescents who switched at least once between both therapy modalities, the number of hospital days associated with injection therapy was higher than with pump therapy, whatever the direction of the switch (for all patients with therapy switch: 4.6 [4.3-5.0] vs. 3.9 [3.6-4.2] days/PY, $P<0.0001$; results detailed by direction of the switch: Fig. 1d). However, if we consider that most hospital days in case of hospitalization with therapy switch should be allocated to the new therapy, the advantage of the pump therapy in terms of reduced hospital days was no longer evident for patients with therapy switch (sensitivity analysis, results non shown here).

Regarding the most frequent admission causes, the numbers of hospital days per person-year due to diabetes education were similar with pump or injection therapy (Fig. 2).

Table 1 Characteristics of the study population in the period of diagnosis

\begin{tabular}{|c|c|c|c|c|}
\hline & All patients $(n=22,434)$ & Injection therapy $(n=18,080)$ & Pump therapy $(n=4,354)$ & $P$ values $^{\mathrm{a}}$ \\
\hline Girls, $n(\%)$ & $10,185(45.4)$ & $8,073(44.7)$ & $2,111(48.5)$ & $<0.0001$ \\
\hline Age, years (median, IQR) & $9.7(6.0-12.9)$ & $10.9(8.1-13.5)$ & $3.7(2.4-5.3)$ & $<0.0001$ \\
\hline Migration background, $n(\%)$ & $4,980(22.2)$ & $3,978(22.0)$ & $1,002(23.0)$ & n.s. $(0.15)$ \\
\hline BMI SDS (median, IQR) & $0.03(-0.56$ to 0.70$)$ & $-0.03(-0.63$ to 0.66$)$ & $0.29(-0.21$ to 0.86$)$ & $<0.0001$ \\
\hline HbA1c, \% (median, IQR) & $11.0(9.5-12.6)$ & $11.2(9.7-12.9)$ & $10.1(8.9-11.5)$ & $<0.0001$ \\
\hline
\end{tabular}

$I Q R$ interquartile range. Migration background is defined as birth of the patient himself or at least one of his parents outside of Germany. BMI SDS standard deviation score of body mass index $\left(\mathrm{kg} / \mathrm{m}^{2}\right)$

${ }^{\text {a }}$ Comparison between patients with pump or injection therapy using Wilcoxon test for continuous variables and $X^{2}$ test for variables with binomial distribution 
Table 2 Number of hospital days associated with injection vs. pump therapy in the period of diagnosis

\begin{tabular}{|c|c|c|c|}
\hline & Injection therapy $(n=18,080)$ & Pump therapy $(n=4,354)$ & $P$ values \\
\hline \multicolumn{4}{|l|}{ Number of hospital days at diabetes onset $(95 \% \mathrm{CI})^{\text {a }}$} \\
\hline Unadjusted & $12.7(12.4-12.9)$ & $14.0(13.7-14.3)$ & $<0.0001$ \\
\hline Adjusted for sex, age group, and migration background & $12.8(12.5-13.1)$ & $13.6(13.3-13.9)$ & $<0.0001$ \\
\hline
\end{tabular}

${ }^{\text {a }}$ Mean estimates from linear regression models, with diabetes center as random effect

Migration background is defined as birth of the patient himself or at least one of his parents outside of Germany

However, the numbers of days due to DKA or severe hypoglycemia associated with injection therapy were significantly higher than those associated with pump therapy (Fig. 2, both $P$ $<0.0001$ ).

\section{Discussion}

This retrospective analysis of real-world data of 48,756 children and adolescents with type 1 diabetes over a period of 10 years in Germany showed different results for the number of hospital days associated with the type of therapy in the period of diagnosis and during the subsequent course of the disease. Whereas the length of the hospital stays was longer with pump therapy than with injection therapy in the period of diagnosis, the number of hospital days per person-year was in contrast lower with pump therapy during the subsequent course of the disease. Both results were robust, even after adjustment for sex, age group, and migration background for the period of diagnosis, or after stratification by age group, sex, migration status, or switch of therapy for the analysis during the subsequent course of the disease.

In the period of diagnosis, children with pump therapy were younger than those with injection therapy. This result is coherent with the German guidelines, which recommend pump therapy for all newborns, infants, and preschoolers [17]. For these children in Germany, insulin pump therapy is often initiated during the first hospitalization, immediately after the diagnosis of diabetes is made [12]. Compared to older children or adolescents, preschool children often have longer hospital stays [18] and they receive with their parents more education sessions [11]. Thus, the younger age of the pump users in the period of diagnosis may partly explain the longer hospital stays. However, the result was similar after adjustment for age groups, so that the additional time spent in hospital cannot be completely explained by the younger age.

Another plausible reason for longer hospital stays at diagnosis is the additional education and management for pump use compared to injection therapy. Indeed in Germany (in contrast to other countries, e.g., the USA), inpatient management of newly diagnosed diabetes including diabetes education is common, regardless of the choice of the therapy [11, 18]. However, diabetes education for parents of children using a pump therapy might require more time to learn how to manage the pump and adjust the dosages.

In the analysis during the subsequent course of the disease, we found - in contrast to the period of diagnosis that the number of hospital days per person-year was lower with insulin pump therapy than with injection therapy. The difference was small (less than one day per person-year), but estimated over a long period in a large population (201,442 patientyears), and robust even after different stratifications by age group, sex, migration background, or presence/absence of therapy switch, indicating that the results are independent of these characteristics. In particular, it is noteworthy that a similar result was obtained in patients who switched one or more times between insulin injections and pump, whatever the direction of the switch. In this sub-analysis, comparisons were performed within the same patients. Thus, even unmeasured demographic and psychosocial characteristics which are expected to influence the outcomes (e.g., family support, education level, deprivation, or socioeconomic status) were the same, and could not have influenced the findings. Nevertheless, a sensitivity analysis showed that the results for the patients with switch depend on the allocation of the hospital days for hospitalizations with therapy switch. If instead of $50 \%, 70 \%$ or $80 \%$ of these hospital days were allocated to the new therapy (i.e., for most of the patients, pump therapy), then the long-term advantage of the pump therapy was no longer evident for the patients with therapy switch, but if hospital stays with therapy switch are not taken into account (or with $50-50 \%$ of the days allocated to the previous and to the new therapy), then the use of pump therapy was associated with less hospital days, even in patients with therapy switch.

Our results indicate a reduced number of hospital days due to DKA or severe hypoglycemia in association with pump use. This is in line with the results of a large populationbased cohort study, reporting an association between the use of insulin pump and lower rates of acute complications in patients under 20 years of age [5]. However, in this study and in our analysis, the education level or motivation of the family was not taken into account, so that a residual selection bias could not have been completely excluded. Older children who start pump therapy may come more frequently from higher motivated families, which can be a factor for less 


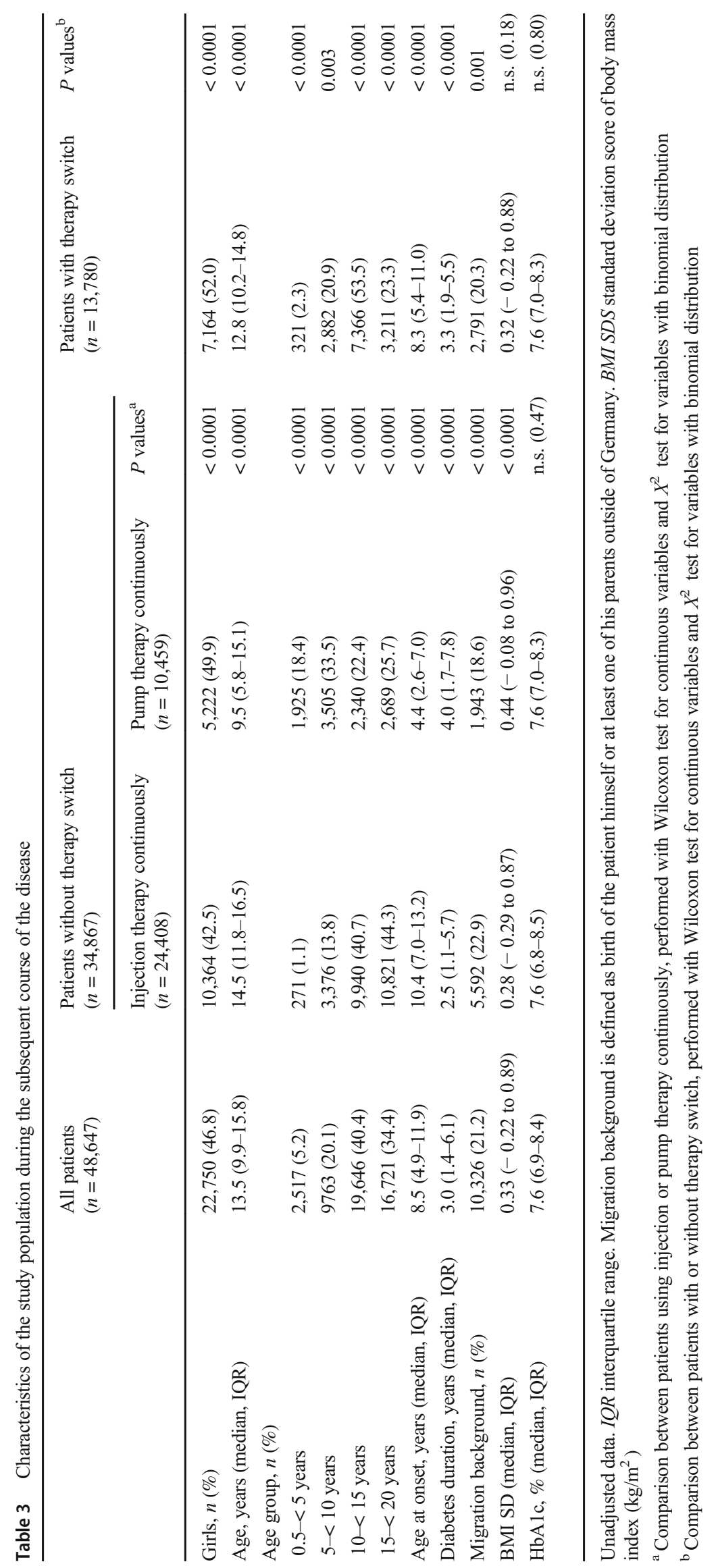


a

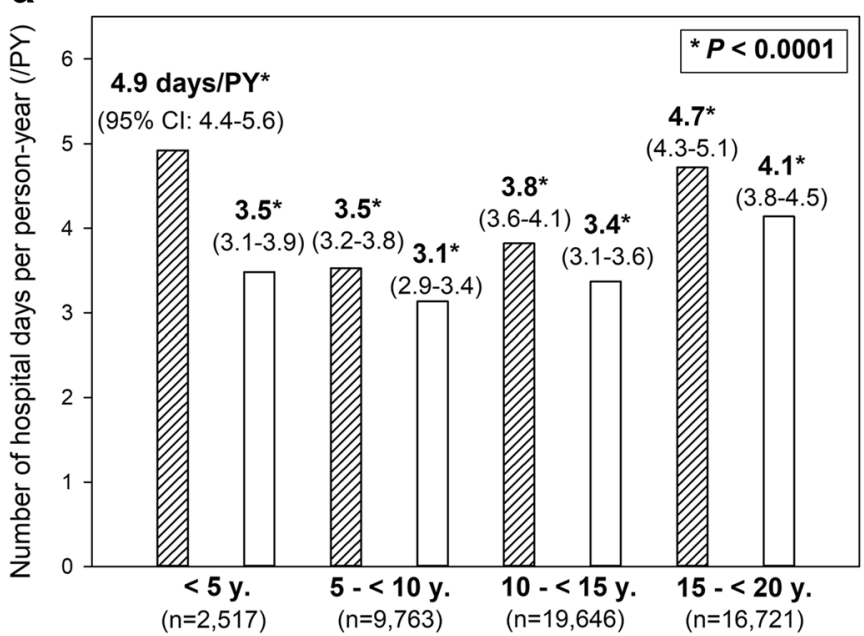

c

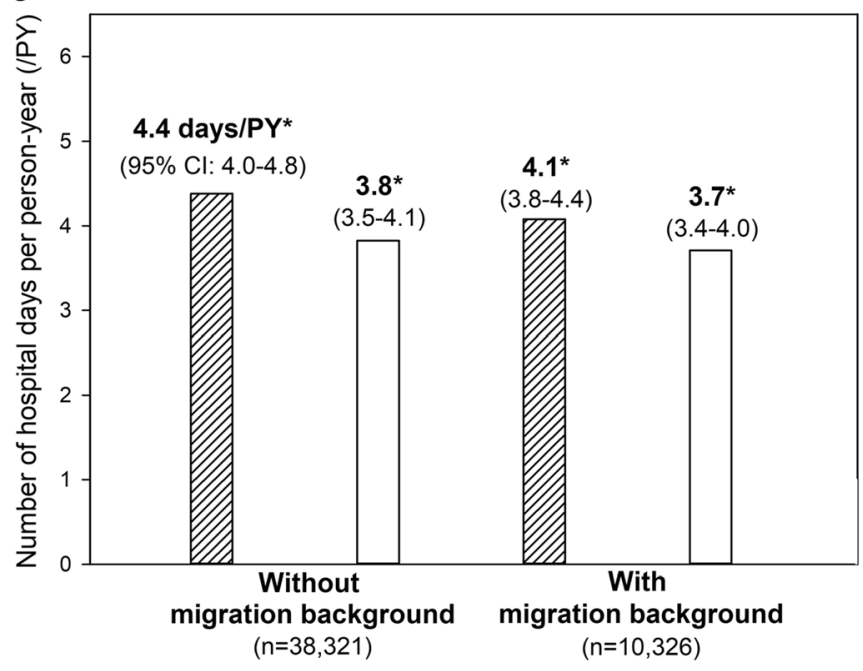

b

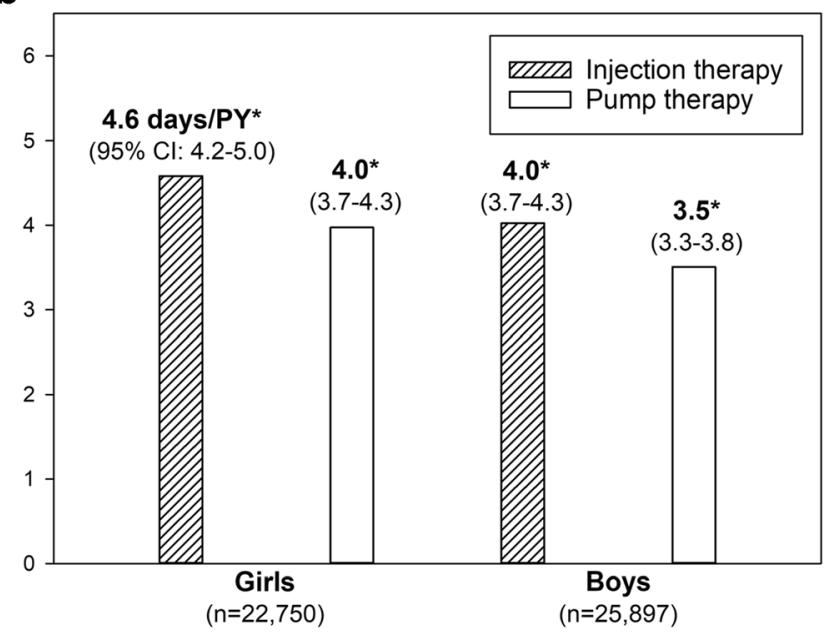

d

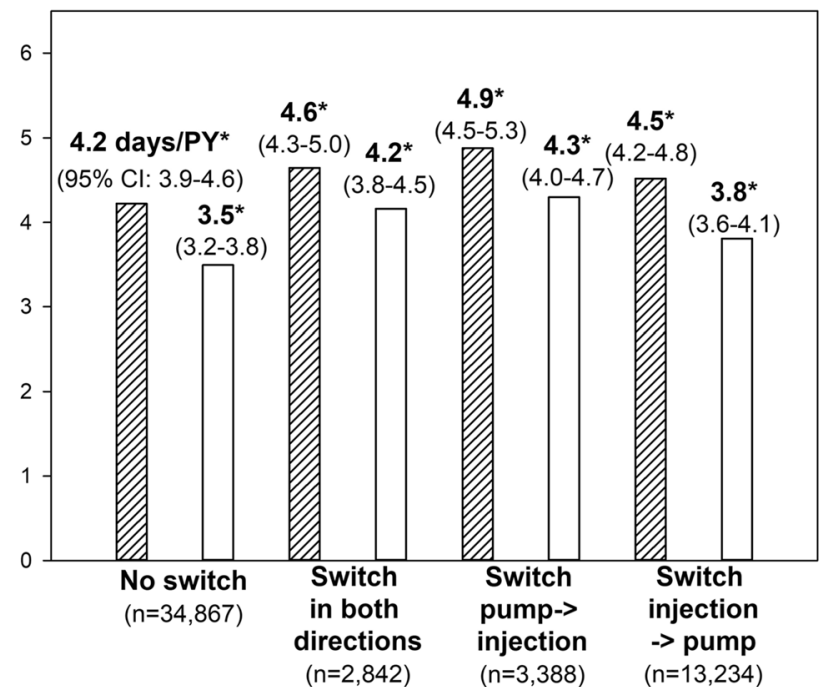

Fig. 1 Number of hospital days associated with injection vs. pump therapy during the subsequent course of diabetes. Legend: mean estimates of Poisson regression models with 95\%, CI. All comparisons between injection therapy and pump therapy groups are significant $(P<0.0001)$

complications and less hospitalizations. In the present analysis, pump use was associated with a reduced number of hospital days, including in the subgroup of patients with migration background. However, a selection bias based on the motivation of the family for the use of diabetes technology is also possible in the subgroup of patients with migration background.

We found longer hospitalizations at diagnosis for pump users, but reduced hospital days in the long-term. Similarly, a pragmatic randomized controlled trial conducted in patients under 15 years of age in the UK concluded that insulin pump therapy is not cost-effective during the first year after diagnosis (including higher costs related to inpatient stays) [19]. However, a systematic review indicated that the higher lifetime direct costs associated with the pump therapy were partially offset by cost-savings from reduced diabetes-related complications, and that insulin pump therapy was costeffective for patients with poor glycemic control or problematic hypoglycemia with injections [20].

The major strength of this study is the use of real-world data of a large population of children and adolescents with type 1 diabetes, documented over 10 years in a nationwide registry. The DPV database covers more than $90 \%$ of all pediatric patients with type 1 in Germany [3], and thus, the data used can be considered as representative. Although a risk of residual selection bias cannot completely be excluded in observational studies, large population-based data are particularly valuable to assess relatively rare outcomes like hospital admissions in pediatric type 1 diabetes. Another strength of the present analysis is that we did not exclude patients with therapy switch, contrary to precedent studies [5]. Thus, individual variations in pump and injection use with different 
Fig. 2 Number of hospital days associated with injection vs. pump therapy during the subsequent course of diabetes, by admission cause. Legend: mean estimates of Poisson regression models with $95 \%$, CI

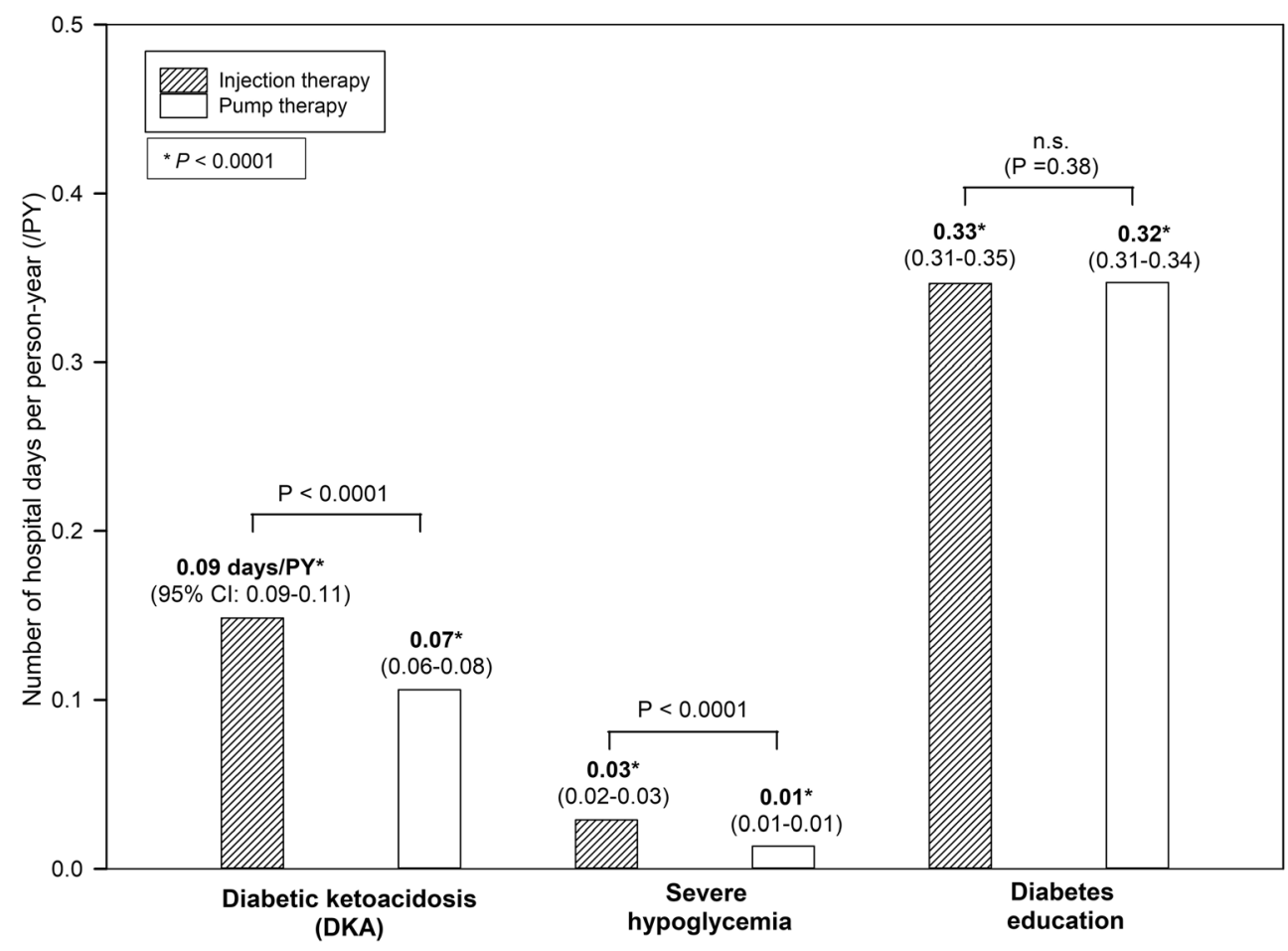

durations were taken into account, reflecting the real-world complexity.

Nevertheless, this analysis has limitations. In the DPV registry, parents' education level is incompletely documented and household income is not available. We assume that such socio-economic baseline characteristics, which are known to have an impact on the access to diabetes technology [21], are not equally distributed between the patients using pump therapy and those using injection therapy. To address this limitation, we performed the analysis in more than 13,000 patients with one or many therapy switches and report similar results in these patients who used both therapy modalities. Moreover, we performed multiple regression analysis in order to adjust for age group, sex, and migration in the period of diagnosis, and used stratification methods for the analysis during the course of the disease. Overall, our results were robust.

Due to historical reasons and funding of diabetes care, some countries still have high hospitalization rates in pediatric diabetes. In the near future, patient access to advanced technology, like automated insulin delivery (close loop) systems, is anticipated to improve [22], and thus, the importance of diabetes technology education will increase. By consideration of the high costs related to inpatient education and training, the diabetes community should continue to discuss opportunities of promoting outpatient approaches [23, 24]. Nevertheless, the present study underlines that, even in countries with high hospitalization rates and hospitalizations at diagnosis of longer duration, the use of pump therapy is associated with a lower number of hospital days in the long-term, especially for children under 5 years of age.
Acknowledgments Special thanks to A. Hungele and R. Ranz for support and the development of the DPV documentation software, and K. Fink and E. Bollow for the DPV data management (Institute of Epidemiology and Medical Biometry, ZIBMT, University of Ulm respectively). Furthermore, we thank all participating centers in the DPV initiative, especially the centers contributing data to this investigation and their patients.

Authors' contributions M.A. and R.W.H. designed the study. M.A. analyzed the study data, wrote the manuscript, and created the figures. B.K., A.N, T.K., S.A.W, C.G., G.K., E.M.G., G.D., and R.W.H. contributed to the discussion and reviewed the manuscript.

Funding Open Access funding enabled and organized by Projekt DEAL. The DPV registry and this analysis are supported by the German Center for Diabetes Research (DZD, grant number: 82DZD0017G). Further financial support for the DPV registry was provided by the German Diabetes Association (DDG), the German Robert Koch Institute (RKI), and by the European Foundation for the Study of Diabetes (EFSD).

Data availability M.A. is the guarantor of this work and, as such, had full access to all the data in the study, and takes responsibility for the integrity of the data and the accuracy of the data analysis.

\section{Compliance with ethical standards}

Conflict of interest The authors declare that they have no conflict of interest.

Ethics approval The Ethics Committee of the Medical Faculty of the University of Ulm (vote number 202/09), as well as the local review boards of participating centers, approved both data collection and analysis of anonymized data from the DPV database. 
Consent to participate Not applicable

\section{Consent for publication Not applicable}

Code availability All statistical analyses were performed with SAS 9.4 (SAS Institute, Cary, NC, USA).

Open Access This article is licensed under a Creative Commons Attribution 4.0 International License, which permits use, sharing, adaptation, distribution and reproduction in any medium or format, as long as you give appropriate credit to the original author(s) and the source, provide a link to the Creative Commons licence, and indicate if changes were made. The images or other third party material in this article are included in the article's Creative Commons licence, unless indicated otherwise in a credit line to the material. If material is not included in the article's Creative Commons licence and your intended use is not permitted by statutory regulation or exceeds the permitted use, you will need to obtain permission directly from the copyright holder. To view a copy of this licence, visit http://creativecommons.org/licenses/by/4.0/.

\section{References}

1. Foster NC, Beck RW, Miller KM, Clements MA, Rickels MR, DiMeglio LA, Maahs DM, Tamborlane WV, Bergenstal R, Smith E, Olson BA, Garg SK (2019) State of type 1 diabetes management and outcomes from the T1D exchange in 2016-2018. Diabetes Technol Ther. https://doi.org/10.1089/dia.2018.0384

2. Birkebaek NH, Drivvoll AK, Aakeson K, Bjarnason R, Johansen A, Samuelsson U, Skrivarhaug T, Thorsson AV, Svensson J (2017) Incidence of severe hypoglycemia in children with type 1 diabetes in the Nordic countries in the period 2008-2012: association with hemoglobin A 1c and treatment modality. BMJ Open Diabetes Res Care. https://doi.org/10.1136/bmjdrc-2016-000377

3. van den Boom L, Karges B, Auzanneau M, Rami-Merhar B, Lilienthal E, von Sengbusch S, Datz N, Schroder C, Kapellen T, Laimer M, Schmid SM, Muller H, Wolf J, Holl RW (2019) Temporal trends and contemporary use of insulin pump therapy and glucose monitoring among children, adolescents, and adults with type 1 diabetes between 1995 and 2017. Diabetes Care 42: 2050-2056. https://doi.org/10.2337/dc19-0345

4. Sherr JL, Hermann JM, Campbell F, Foster NC, Hofer SE, Allgrove J, Maahs DM, Kapellen TM, Holman N, Tamborlane WV, Holl RW, Beck RW, Warner JT, T1D Exchange Clinic Network, the DPV Initiative, and the National Paediatric Diabetes Audit and the Royal College of Paediatrics and Child Health registries (2016) Use of insulin pump therapy in children and adolescents with type 1 diabetes and its impact on metabolic control: comparison of results from three large, transatlantic paediatric registries. Diabetologia 59:87-91. https://doi.org/10.1007/s00125015-3790-6

5. Karges B, Schwandt A, Heidtmann B, Kordonouri O, Binder E, Schierloh U, Boettcher C, Kapellen T, Rosenbauer J, Holl RW (2017) Association of insulin pump therapy vs insulin injection therapy with severe hypoglycemia, ketoacidosis, and glycemic control among children, adolescents, and young adults with type 1 diabetes. JAMA 318:1358-1366. https://doi.org/10.1001/jama. 2017.13994

6. Steineck I, Cederholm J, Eliasson B, Rawshani A, Eeg-Olofsson K, Svensson AM, Zethelius B, Avdic T, Landin-Olsson M, Jendle J, Gudbjornsdottir S, Swedish National Diabetes Register (2015) Insulin pump therapy, multiple daily injections, and cardiovascular mortality in 18,168 people with type 1 diabetes: observational study. BMJ 350:h3234. https://doi.org/10.1136/bmj.h3234
7. Mueller-Godeffroy E, Vonthein R, Ludwig-Seibold C, Heidtmann B, Boettcher C, Kramer M, Hessler N, Hilgard D, Lilienthal E, Ziegler A, Wagner VM, German Working Group for Pediatric Pump Therapy (agip) (2018) Psychosocial benefits of insulin pump therapy in children with diabetes type 1 and their families: the pumpkin multicenter randomized controlled trial. Pediatr Diabetes 19:1471-1480. https://doi.org/10.1111/pedi.12777

8. Toresson Grip E, Svensson AM, Miftaraj M, Eliasson B, Franzen S, Gudbjornsdottir S, Steen Carlsson K (2019) Real-world costs of continuous insulin pump therapy and multiple daily injections for type 1 diabetes: a population-based and propensity-matched cohort from the Swedish national diabetes register. Diabetes Care 42:545552. https://doi.org/10.2337/dc18-1850

9. AbdulAziz YH, Al-Sallami HS, Wiltshire E, Rayns J, Willis J, McClintock J, Medlicott N, Wheeler BJ Paediatric Society of New Zealand Diabetes Clinical Network (2019) Insulin pump initiation and education for children and adolescents - a qualitative study of current practice in New Zealand. J Diabetes Metab Disord. https://doi.org/10.1007/s40200-019-00390-6

10. Tiberg I, Lindgren B, Carlsson A, Hallstrom I (2016) Costeffectiveness and cost-utility analyses of hospital-based home care compared to hospital-based care for children diagnosed with type 1 diabetes; a randomised controlled trial; results after two years' follow-up. BMC Pediatr. https://doi.org/10.1186/s12887-016-0632-8

11. Konrad K, Vogel C, Bollow E, Fritsch M, Lange K, Bartus B, Holl RW, German/Austrian DPV Initiative and the competence network of diabetes (2016) Current practice of diabetes education in children and adolescents with type 1 diabetes in Germany and Austria: analysis based on the German/Austrian DPV database. Pediatr Diabetes 17:483-491. https://doi.org/10.1111/pedi. 12330

12. Ziegler R, Neu A (2018) Diabetes in childhood and adolescence. Dtsch Arztebl Int. https://doi.org/10.3238/arztebl.2018.0146

13. Rosenbauer J, Dost A, Karges B, Hungele A, Stahl A, Bachle C, Gerstl EM, Kastendieck C, Hofer SE, Holl RW, DPV Initiative and the German BMBF Competence Network Diabetes Mellitus (2012) Improved metabolic control in children and adolescents with type 1 diabetes: a trend analysis using prospective multicenter data from Germany and Austria. Diabetes Care 35:80-86. https://doi.org/10. 2337/dc11-0993

14. Schaffrath Rosario AS, Kurth BM, Stolzenberg H, Ellert U, Neuhauser H (2010) Body mass index percentiles for children and adolescents in Germany based on a nationally representative sample (KiGGS 2003-2006). Eur J Clin Nutr 64:341-349. https:// doi.org/10.1038/ejcn.2010.8

15. Cole TJ, Green PJ (1992) Smoothing reference centile curves: the LMS method and penalized likelihood. Stat Med 11:1305-1319. https://doi.org/10.1002/sim.4780111005

16. Jacobsen LM, Larsson HE, Tamura RN, Vehik K, Clasen J, Sosenko J, Hagopian WA, She JX, Steck AK, Rewers M, Simell O, Toppari J, Veijola R, Ziegler AG, Krischer JP, Akolkar B, Haller MJ, TEDDY Study Group (2019) Predicting progression to type 1 diabetes from ages 3 to 6 in islet autoantibody positive TEDDY children. Pediatr Diabetes. https://doi.org/10.1111/pedi.12812

17. Neu A, Burger-Busing J, Danne T, Dost A, Holder M, Holl RW, Holterhus PM, Kapellen T, Karges B, Kordonouri O, Lange K, Muller S, Raile K, Schweizer R, Sengbusch SV, Stachow R, Wagner V, Wiegand S, Ziegler R (2019) Diagnosis, therapy and follow-up of diabetes mellitus in children and adolescents. Exp Clin Endocrinol Diabetes. https://doi.org/10.1055/a-1018-8963

18. Auzanneau M, Rosenbauer J, Icks A, Karges B, Neu A, Ziegler R, Marg W, Kapellen T, Holterhus P, Holl R (2019) Hospitalization in pediatric diabetes: a nationwide analysis of all admission causes for Germany in 2015. Exp Clin Endocrinol Diabetes. https://doi.org/ 10.1055/a-0972-1060 Online ahead of print

19. Blair JC, McKay A, Ridyard C, Thornborough K, Bedson E, Peak M, Didi M, Annan F, Gregory JW, Hughes DA, Gamble C, SCIPI 
investigators (2019) Continuous subcutaneous insulin infusion versus multiple daily injection regimens in children and young people at diagnosis of type 1 diabetes: pragmatic randomised controlled trial and economic evaluation. BMJ 365:11226. https://doi.org/10. 1136/bmj.11226

20. Roze S, Smith-Palmer J, Valentine W, de Portu S, Norgaard K, Pickup JC (2015) Cost-effectiveness of continuous subcutaneous insulin infusion versus multiple daily injections of insulin in Type 1 diabetes: a systematic review. Diabet Med 32:1415-1424. https:// doi.org/10.1111/dme.12792

21. Addala A, Auzanneau M, Miller K, Maier W, Foster N, Kapellen T, Walker A, Rosenbauer J, Maahs DM, Holl RW (2020) A decade of disparities in diabetes technology use and $\mathrm{HbAlc}$ in pediatric type 1 diabetes: a transatlantic comparison. Diabetes Care. https://doi.org/ $10.2337 / \mathrm{dc} 20-0257$
22. Sherr JL, Tauschmann M, Battelino T, de Bock M, Forlenza G, Roman R, Hood KK, Maahs DM (2018) ISPAD Clinical practice consensus guidelines 2018: diabetes technologies. Pediatr Diabetes. https://doi.org/10.1111/pedi.12731

23. Clar C, Waugh N, Thomas S (2007) Routine hospital admission versus out-patient or home care in children at diagnosis of type 1 diabetes mellitus. Cochrane Database Syst Rev. https://doi.org/10. 1002/14651858.CD004099.pub2

24. Tonyushkina KN, Visintainer PF, Jasinski CF, Wadzinski TL, Allen HF (2014) Site of initial diabetes education does not affect metabolic outcomes in children with T1DM. Pediatr Diabetes. https://doi.org/10.1111/pedi.12069

\section{Affiliations}

\section{Marie Auzanneau ${ }^{1,2}$ (D) $\cdot$ Beate Karges ${ }^{3}$ - Andreas Neu ${ }^{4} \cdot$ Thomas Kapellen $^{5} \cdot$ Stefan A. Wudy ${ }^{6}$. Corinna Grasemann ${ }^{7}$. Gabriele Krauch $^{8}$ • Eva Maria Gerstl ${ }^{9}$ - Gerhard Däublin ${ }^{10} \cdot$ Reinhard W. Holl $^{1,2}$}

1 Institute of Epidemiology and Medical Biometry, ZIBMT, University of Ulm, Albert-Einstein-Allee 41, D89081 Ulm, Germany

2 German Center for Diabetes Research (DZD), Neuherberg, Germany

3 Division of Endocrinology and Diabetes, Medical Faculty, RWTH Aachen University, Aachen, Germany

4 University Children's Hospital Tübingen, Tübingen, Germany

5 Department of Women and Child Health, Hospital for Children and Adolescents, University of Leipzig, Leipzig, Germany

6 Division of Pediatric Endocrinology and Diabetology, Center of Child and Adolescent Medicine, Justus Liebig University, Giessen, Germany
7 St. Josef-Hospital, Klinikum der Ruhr-Universität, Bochum, Germany

8 Division of Pediatric Endocrinology and Diabetology, Center of Child and Adolescent Medicine, University Medicine, Mannheim, Germany

9 Children's Hospital Passau, Passau, Germany

10 Children's Hospital Aurich, Aurich, Germany 